\title{
Predictors of Neonatal Deaths in Ashanti Region of Ghana: A Cross-Sectional Study
}

\author{
Gertrude Nancy Annan (iD) ${ }^{1}$ and Yvonne Asiedu ${ }^{2}$ \\ ${ }^{1}$ Nursing and Midwifery Training College, Kumasi, Ghana \\ ${ }^{2}$ SDA Midwifery Training College, Asamang, Ghana \\ Correspondence should be addressed to Gertrude Nancy Annan; afuaannan@outlook.com
}

Received 4 October 2017; Revised 20 February 2018; Accepted 20 March 2018; Published 29 April 2018

Academic Editor: Ronald J. Prineas

Copyright ( 2018 Gertrude Nancy Annan and Yvonne Asiedu. This is an open access article distributed under the Creative Commons Attribution License, which permits unrestricted use, distribution, and reproduction in any medium, provided the original work is properly cited.

\begin{abstract}
Background. Neonatal mortality continues to be a public health problem, especially in sub-Saharan Africa. This study was conducted to assess the maternal, neonatal, and health system related factors that influence neonatal deaths in the Ashanti Region, Ghana. Methods. 222 mothers and their babies who were within the first 28 days of life on admission at Mother and Baby unit (MBU) at the Komfo Anokye Teaching Hospital (KATH) in Kumasi, Ashanti Region of Ghana, were recruited through systematic random sampling. Data was collected by face to face interviewing using open and closed ended questions. A logistic regression analysis was conducted to determine the influence of proximal and facility related factors on the odds of neonatal death. Results. Out of the 222 mothers, there were 115 (51.8\%) whose babies did not survive. Majority, 53.9\%, of babies died within 1-4 days, 31.3\% within 5-14 days, and $14.8 \%$ within 15-28 days. The cause of death included asphyxia, low birth weight, congenital anomalies, infections, and respiratory distress syndrome. Neonatal deaths were influenced by proximal factors (parity, duration of pregnancy, and disease of the mother such as HIV/AIDS), neonatal factors (birth weight, gestational period, sex of baby, and Apgar score), and health related factors (health staff attitude, supervision of delivery, and hours spent at labour ward). Conclusion. This study shows a high level of neonatal deaths in the Ashanti Region of Ghana. This finding suggests the need for health education programmes to improve on awareness of the dangers that can militate against neonatal survival as well as strengthening the health system to support mothers and their babies through pregnancy and delivery and postpartum to help improve child survival.
\end{abstract}

\section{Introduction}

Child survival remains an urgent concern globally [1]. Despite the enormous progress made in improving child survival, this has not reflected in the decline in neonatal mortality $[1,2]$. Since 1990, under-five mortality rate has been reduced nearly by half from 90 to 46 deaths per 1,000 live births in 2013 and the global under-five mortality rate is currently falling faster than at any other time over the past two decades [1]. The decline in neonatal deaths has however been slower than the decline in the postneonatal (1-59 months) mortality rate, leading to neonatal deaths currently representing a larger share of the total under-five deaths than in 1990. In 2013, about $44 \%$ of all under-five deaths occurred in the first 28 days of life, increasing from 37\% in 1990 [1]. This proportion rose to $45 \%$ in 2015 [3]. Although every region in the world is experiencing an increase in the proportion of neonatal deaths, the burden is highest in West and Central Africa, where the risk of a baby dying within the first 28 days of life is almost 10 times higher than the risk facing a baby born in a high-income country [1].

In Ghana, neonatal mortality rate in the most recent period (2009-2014) stood at 29 deaths per 1,000 live births [4]. This rate is 2.2 times the postneonatal rate (13 deaths per 1,000 live births) during the same period. This shows a slower pace in reduction than infant and child mortality and has resulted in an increase in the contribution of neonatal deaths to infant deaths from $53 \%$ in 1998 to $71 \%$ in 2014 . Sixty-eight percent of all deaths among children under age 5 in Ghana take place before a child's first birthday, with $48 \%$ occurring during the first month of life. This means that one in every 24 children in Ghana dies before reaching age 1, while one in every 17 does not survive to her or his fifth birthday [4]. 
The WHO's standard definition of neonatal death is the death of any live born infant within 28 days of his/her birth [5]. Almost $66 \%$ of neonatal deaths occur in the first week of life. Of those who die within the first week, approximately $66 \%$ die in the first 24 hours of life [6]. The initial 24 hours of a child's life are the most dangerous with over one million newborns around the world dying each year on their first and only day of life [7]. Without urgent action, the progress in under-five mortality could stall without urgent action to tackle the high rate of newborns dying, which now account for more than 4 in 10 child under-five deaths [7]. The causes of neonatal deaths are numerous and are related to pregnancy, delivery, and infections. Each of these factors accounts for about one-third of newborn deaths. Birth intervals of less than 36 months significantly increase the risk of low birth weight, premature babies, and neonatal death. Asphyxia and congenital anomalies, infections, hemorrhage, and respiratory distress syndrome also contribute to a high proportion of neonatal deaths $[8,9]$.

Neonatal and maternal deaths place a significant burden on health systems as well as on women and families. Making motherhood safer is critical to saving newborns. Research shows that a significant number of neonatal deaths could be prevented if all women received good quality antenatal care as well as good quality care during delivery and the postpartum period. Characteristics of the health system including attitudes of staff, availability of care, and place of delivery contribute to maternal and delivery outcomes [10]. Even though maternity services are largely said to be "free" at government facilities, associated hidden costs contribute to low utilization of maternity services. According to UNFPA reports [11], many factors complicate women's access to skilled care in the sub-Saharan African region. The report further explained that often women give birth at home because of the prohibitive cost of medical care or cultural beliefs that promote home-based delivery. Some simply lack confidence in the health system. Difficult geographic terrain and limited transportation may present obstacles to reaching a skilled attendant $[12,13]$.

Whiles the national neonatal mortality rate also has seen a decrease from 2003 to 2014 [4], the same cannot be said in terms of the regional statistics. The Ashanti Region recorded an increase in neonatal death over the same period (increased by 1.8 per 1000 live births) and the regional rate in 2014 was higher than the national average (42 versus 29 per 1000 live births). There is, however, paucity of evidence on the maternal and child level predictors of neonatal mortality in the Ashanti region. This study was conducted to assess the maternal, neonatal, and health system related factors that influence neonatal deaths in the Ashanti Region, Ghana.

\section{Methods}

2.1. Study Design and Setting. The research was a quantitative descriptive survey conducted at the Mother and Baby unit (MBU) at the Komfo Anokye Teaching Hospital (KATH) in Kumasi, Ashanti Region of Ghana. The city of Kumasi is the capital of the Ashanti Region and the centre of the Kumasi Metropolitan District in Ghana. KATH is the second-largest hospital in the country and the only tertiary health institution in the Ashanti Region. It is the main referral hospital for the Ashanti, Brong Ahafo, and Northern, Upper East and Upper West, and Western regions as well as for neighboring countries. The hospital was built in 1954 as the Kumasi Central Hospital. It was later named Komfo Anokye Hospital after Okomfo Anokye, a legendary fetish priest of the Ashanti. It was converted into a teaching hospital in 1975 to train nurses, doctors, medical technologist, and paramedics. It is affiliated to the School of Medical Sciences of the Kwame Nkrumah University of Science and Technology (KNUST).

The MBU is under the Child Health directorate, one of the 11 directorates of the hospital. It has a bed capacity of seventyone (71) cots and six (6) incubators and admits babies from day of delivery to about 3 months. The unit runs a twentyfour (24) hour emergency service throughout the week. Cases are referred from regional hospitals, district hospitals, general practitioners, and maternity homes and from other regions. At the MBU, there are three subunits, the high dependency, premature/low dependency, and septic. The most common cases admitted at MBU are preterm/low birth weight and asphyxia. However neonatal infections, birth traumas, congenital abnormalities, jaundice, Vitamin K deficiency, and heart failure cases are also admitted, HIV/AIDS being the least case admitted.

2.2. Sampling Techniques and Sample Size. The study population was mothers and their babies who were within the first 28 days of life on admission at MBU, KATH, Kumasi.

Sample size was estimated using Cochran's sample size formula [14]. The prevalence of neonatal mortality in the general population was assumed to be $14 \%$.

As per the formula,

$$
N=\frac{Z^{2} P q}{d^{2}}
$$

where

$N$ is sample size

$Z$ is the reliability coefficient for $95 \%$ confidence level set at 1.96

$P$ is proportion of babies who die

$q=1-P=86.0 \%$ or 0.86

$d$ is degree of freedom

$$
N=\frac{1.96^{2} \times(0.14) \times(0.86)}{0.05^{2}}=185 .
$$

Considering nonresponse of $20 \%$, we arrived at total of 222.

A systematic random sampling technique was used to recruit study participants, by defining a random starting point and a fixed sampling interval. Based on the number of expected attendance at the facility and the period of data collection, the average respondents needed per day were estimated. Mothers with their babies within 28 days of life and who consented to be part of the study were randomly selected. 
During the visit hours, the first participant was identified and interviewed as the starting point followed by the $K$ th respondent. In cases when babies did not meet the inclusion criteria, the next and following participants were contacted. This was repeated until the required sample size was attained.

2.3. Data Collection Tools. A face to face interview using open and closed ended questions was adopted. Three (3) field assistants were recruited and trained in the data collection techniques and skills. Participants were recruited daily and the questionnaire was administered. All respondents were made to answer the same questions which were constructed in English. However for respondents who could not read and write, questions were asked in the dialect and their responses were written. Difficult technical terms were avoided in the preparation of the questionnaire. The field assistants were trained to ensure standardization of the questions across sites.

The study instrument (questionnaires) was pretested in Suntreso Government Hospital which has similar characteristics as the study site. This was done to check the clarity, consistency, and acceptability of people other than those interviewed for the study. This was further to train the interviewers and also ensure that the questionnaire met the stated objective. After pretesting, problems such as ambiguity associated with the questionnaire were rectified.

2.4. Assessment of Neonatal Mortality. Neonatal mortality was defined as death of a newborn within 28 days of his/her birth. A checklist was developed for all neonates admitted to the MBU during the period of the study and all of the neonates among that group who died before they were discharged from the hospital. The checklist included various characteristics of the neonates, such as the type of delivery (vaginal or Caesarian section), birth weight, single or multiple births, diagnoses of any diseases, and the duration of survival. These checklists were completed based on the available medical records.

2.5. Data Handling and Analysis. Regular verification and validation of data were done with all inconsistencies being checked and resolved with the researcher, research assistants, and the data entry clerk. All data were entered into and analysed with SPPSS Version 22 Software [15]. Result of the analysis were generated using descriptive and some analytical statistics. Bivariate associations were tested using Pearson chi-square or Fischer's exact test. Univariable and multivariable logistic regression analyses were also conducted to determine the influence of proximal and facility related factors on the odds of neonatal mortality. Proximal risk factors are risk factors that precipitate a condition. They represent an immediate vulnerability for a particular condition or event and they represented the maternal and neonatal factors in this study. The proximal factors considered in this study were maternal factors (age, parity, number of children, birth interval, duration of pregnancy, and disease of mother) and neonatal factors (birth weight, gestational period, sex, birth anomaly, Apgar score, respiratory distress, and crying immediately after birth). The health related factors were ANC visits, attitude of health staff, waiting time, delivery supervision, and labour conditions.

\section{Ethical Considerations}

Ethical clearance for this study was obtained from Department of Community Health-KNUST, the Ethics Committee of KNUST, and Komfo Anokye Teaching Hospital. In addition, written and informed consent was obtained from the individuals who agreed to be part of the study. Privacy and confidentiality were ensured during data collection and assured afterwards.

\section{Results}

4.1. Background Characteristics of the Respondents. The mean (standard deviation, SD) age of respondents was 22 years (0.710) and majority $50.9 \%$ of respondents interviewed were between the ages of 21 and 30 years, Table 1. Majority of the mothers had basic education (60.8\%), were Christians $(73.4 \%)$, and were married (62.6\%). Fifty-nine mothers (26.6\%) had monthly income less than GH\$100.00. Traders formed $29.3 \%$ of respondents.

Babies of 107 mothers, representing 48.2\%, survived, while babies of 115 mothers (51.8\%) died. Among mothers whose babies did not survive, the majority, $54.8 \%$, were in the age group of 21-30 years. There was a statistically significant association $(p=0.046)$ between age of a mother and child survival. Among mothers whose babies did not survive, the majority, $56.5 \%$, were married while $41.7 \%$ were single and there was a statistically significant association $(p=0.034)$ between marital status and child survival. Marital status ( $p=$ $0.034)$ and occupation $(p=0.035)$ of respondents also had a significant association with child survival (Table 1).

4.2. Neonatal Deaths. Majority (53.9\%) of babies died within 1-4 days and $31.3 \%$ within 5-14 days while $14.8 \%$ died within 15-28 days. Most (37.4\%) of the babies died from asphyxia. About $32.7 \%$ also died from low birth weight and $10.3 \%$ died due to prematurity, $9.3 \%$ congenital anomalies, $5.6 \%$ infections, and $3.7 \%$ respiratory distress syndrome (Figure 1).

\subsection{Proximal Factors and Neonatal Death}

4.3.1. Maternal Factors. As described in Table 2, though the age of mother had a significant association with child survival, this was not observed in the logistic regression analysis. In terms of parity, $47.8 \%$ and $47 \%$ of babies who did not survive were of primigravida and multigravida mothers, respectively, $p=0.042$.

Among mothers with duration of pregnancy of $35-40$ weeks, $67.3 \%$ had babies who survived compared to $34.8 \%$ whose children died, $p=0.026$. Regression analysis indicated that mothers with duration of 35-40 weeks of pregnancy had 3.15 higher odds of their babies surviving $(\mathrm{OR}=3.15, \mathrm{CI}=$ $2.21,6.79)$ as compared to those within duration of $24-30$ weeks of pregnancy. The odds of child survival increased to 3.62 in the adjusted model. Babies whose mothers were not hypertensive also had higher odds of survival as compared to those whose mothers were hypertensive (adjusted odds ration $[\mathrm{AOR}]=1.41, \mathrm{CI}=1.20,1.68)$. 
TABLE 1: Background characteristics of the mothers of children who died and those who survived.

\begin{tabular}{|c|c|c|c|c|}
\hline Variable & $\begin{array}{c}\text { Baby survived } n=107 \\
\qquad N(\%)\end{array}$ & $\begin{array}{c}\text { Baby did not survive } \\
n=115 \\
N(\%)\end{array}$ & $\begin{array}{c}\text { Total } n=222 \\
N(\%)\end{array}$ & $p$ value \\
\hline \multicolumn{5}{|l|}{ Age } \\
\hline Mean (SD) & $22(0.710)$ & & & \multirow{5}{*}{0.046} \\
\hline $15-20$ yrs & $15(14.0)$ & $21(18.3)$ & $36(16.2)$ & \\
\hline $21-30 \mathrm{yrs}$ & $50(46.7)$ & $63(54.8)$ & $113(50.9)$ & \\
\hline $31-40$ yrs & $42(39.3)$ & $28(24.3)$ & $70(31.5)$ & \\
\hline Above 40 yrs & $0(0.0)$ & $3(2.6)$ & $3(1.4)$ & \\
\hline \multicolumn{5}{|l|}{ Education } \\
\hline None & $5(4.7)$ & $7(6.1)$ & $12(5.4)$ & \multirow{4}{*}{0.419} \\
\hline Basic & $71(66.4)$ & $64(55.7)$ & $135(60.8)$ & \\
\hline Secondary & 19 (17.8) & $29(25.2)$ & $48(21.6)$ & \\
\hline Tertiary & $12(11.2)$ & $15(13.0)$ & $27(12.2)$ & \\
\hline \multicolumn{5}{|l|}{ Religion } \\
\hline Christian & $83(77.6)$ & $80(69.6)$ & $163(73.4)$ & \multirow{3}{*}{0.582} \\
\hline Islam/Muslim & $22(20.6)$ & $32(27.8)$ & $54(24.3)$ & \\
\hline Traditionalist/others & $2(1.8)$ & $3(2.6)$ & $5(2.3)$ & \\
\hline \multicolumn{5}{|l|}{ Marital status } \\
\hline Single & $32(29.9)$ & $48(41.7)$ & $80(36.0)$ & \multirow{4}{*}{0.034} \\
\hline Separated & $0(0.0)$ & $2(1.7)$ & $2(0.9)$ & \\
\hline Divorced & $1(0.9)$ & $0(0.0)$ & $1(0.05)$ & \\
\hline Married & $74(69.2)$ & $65(56.5)$ & $139(62.6)$ & \\
\hline \multicolumn{5}{|l|}{ Income of mother } \\
\hline Unknown & $59(55.1)$ & $54(47.0)$ & $113(50.9)$ & \multirow{4}{*}{$(0.509)$} \\
\hline Less than $\mathrm{GH} \$ 100$ & $28(26.2)$ & $31(27.0)$ & $59(26.6)$ & \\
\hline $\mathrm{GH} ₫ 100-\mathrm{GH} ₫ 300$ & $14(13.1)$ & $19(16.5)$ & 33 (14.9) & \\
\hline $\mathrm{GH} ₫ 300-\mathrm{GH} \$ 500$ & $6(5.6)$ & $11(9.6)$ & $17(7.7)$ & \\
\hline \multicolumn{5}{|l|}{ Occupation } \\
\hline Self-employed & $18(16.8)$ & $23(20.0)$ & $41(18.5)$ & \multirow{6}{*}{0.035} \\
\hline Housewife/student & $19(17.8)$ & $31(27.0)$ & $50(22.6)$ & \\
\hline Civil servant & $12(11.2)$ & $13(11.3)$ & $25(11.3)$ & \\
\hline Farmer & $1(0.9)$ & $7(6.1)$ & $8(0.6)$ & \\
\hline Trader & $37(34.6)$ & $28(24.3)$ & $65(29.3)$ & \\
\hline Artisans & $20(18.6)$ & $12(10.5)$ & $32(14.5)$ & \\
\hline
\end{tabular}

SD: standard deviation.

Study results indicated that there was a statistically significant association $(p=0.024)$ between mothers with HIV/ AIDS and child survival. Mothers who did not have HIV/ AIDS had 1.53 higher odds of survival $(\mathrm{AOR}=1.53, \mathrm{CI}=1.28$, 1.71) than those who had HIV/AIDS (Table 2).

4.3.2. Neonatal Factors. Average birth weight according to the study was $2.5 \mathrm{~kg}$ while minimum and maximum birth weights were $0.8 \mathrm{~kg}$ and $4.6 \mathrm{~kg}$, respectively, Table 3 . Child survival increased with appreciable increase in baby's weight but declined when baby's weight was more than $3 \mathrm{~kg}$. The analysis indicated that babies whose weights were $3 \mathrm{~kg}$ had 2.75 higher odds of survival $(\mathrm{OR}=2.75, \mathrm{CI}=1.56,3.87)$ as compared to babies whose weight were less than $1 \mathrm{~kg}$. The odds however reduced to 2.29 in the adjusted model.

Out of the 115 babies who did not survive, $68.7 \%$ were preterm, while out of the 107 who survived $81.3 \%$ were term, Table 3. The odds of survival were 5.28 times higher among babies whose gestational period was term $(\mathrm{AOR}=5.28, \mathrm{CI}=$ $3.01,10.05)$ as compared to babies whose gestational period was preterm. Female babies had 1.73 higher odds of survival $(\mathrm{OR}=1.73, \mathrm{CI}=1.48,2.63)$ compared to their male counterparts but this was not significant in the adjusted models.

Baby's Apgar score proved to be relevant in child survival. Most (40.5\%) of the babies had an Apgar score of 4/10-6/10, and about $32.4 \%$ had $7 / 10-10 / 10$, while $27.0 \%$ had $1 / 10-3 / 10$. 


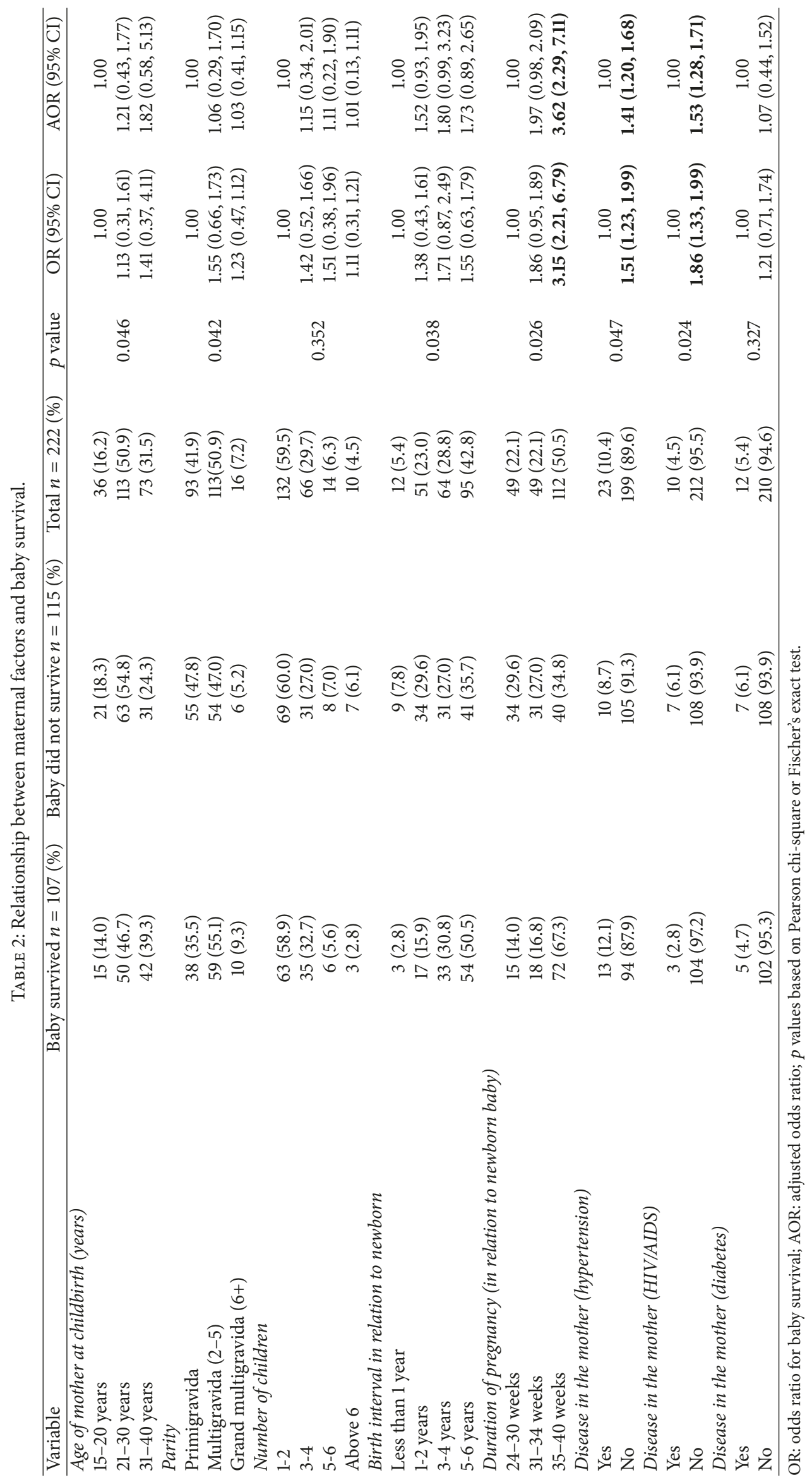




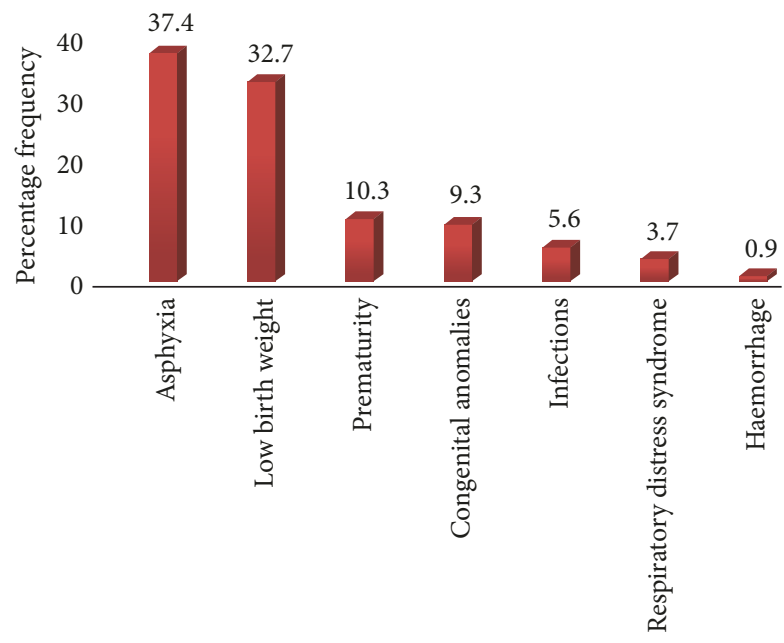

Causes of neonatal death

FIGURE 1: Percentage frequency distribution of causes of death.

Out of 60 babies whose Apgar score was 1/10-3/10, 88.3\% did not survive as compared to $77 \%$ out of 72 babies whose Apgar score was $7 / 10-10 / 10, p=0.038$. Regression analysis showed that babies whose Apgar score was 7/10-10/10 had 4.61 higher odds of survival $(\mathrm{AOR}=4.61, \mathrm{CI}=3.02,8.89)$ as compared to babies whose Apgar score was 1/10-3/10.

Eighty-six percent (86\%) of babies were resuscitated. Although there was a significant association $(p=0.047)$ between neonatal resuscitation and child survival, regression analysis did not yield any marginal variations in the likelihood of child survival and neonatal resuscitation. Results of the study indicated that majority $(66.7 \%)$ of babies did not have respiratory distress. Out of the 74 babies who had respiratory distress $71.6 \%$ did not survive, Table 3.

4.4. Socioeconomic Factors. Most (43.2\%) of the mothers interviewed indicated that the nearest health centre from their residence was between $1 \mathrm{~km}$ and $5 \mathrm{~km}$ away. There was no significant association $(p=0.522$ ) between distance of residence and child survival. Regression analysis did not reveal any variant likelihood of occurrence between child survival and distance of respondents' residence. As shown in Figure 2, 24.3\% walk less than $1 \mathrm{~km}$ to the health centre nearest to respondent, $43.2 \%$ walk between $1 \mathrm{~km}$ and $5 \mathrm{~km}, 10.4 \%$ from $6 \mathrm{~km}$ to $10 \mathrm{~km}$, and $2.1 \%$ above $10 \mathrm{~km}$. Among the 222 interviewed, two hundred and nine representing $94.14 \%$ have registered for the National Health insurance. However, mothers' registration with the NHIS did not have any significant association ( $p=0.215$ ) with child survival. Majority, $74.8 \%$, of the respondents do not know the amount paid during their visit to the health facility. This could be due to the NHIS. $12.6 \%$ paid an amount less than GH\$5.00 and $8.1 \%$ paid $\mathrm{GH} \$ 5.00$ to $\mathrm{GH} \$ 10.00$ while $4.5 \%$ paid more than $\mathrm{GH} \$ 10.00$.

4.5. Health System Related Factors. Majority (50.9\%) of mothers interviewed attended ANC 5-8 times, Table 4. However, some $4.5 \%$ did not attend ANC at all. Majority (51.8\%)

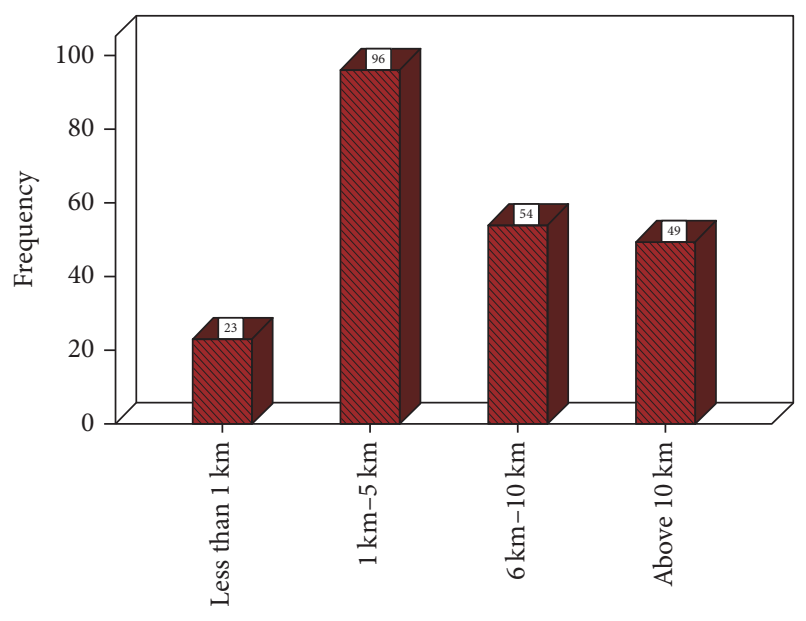

FIGURE 2: Nearest health centre from residence.

of mothers interviewed delivered at KATH, 36.9\% at another health facility (private and public), and $7.7 \%$ at a maternity home. The study revealed that there was a significant $(p=$ 0.038 ) association between place of delivery and child survival.

Among health staff who attended to mothers during ANC visits, majority (74.8\%) were midwives while $19.8 \%$ were doctors. There was a significant association $(p=0.028)$ between health staff attending to mothers at ANC visits and child survival. Neonates whose mothers were attended to by doctors were more likely to survive, as compared to those whose mothers were attend to by nurses. Generally, respondents judged staff attitude as good (54.1\%), very good (37.4\%), and excellent $(2.3 \%)$. There was a significant association $(p=$ 0.028 ) between service providers attitude and child survival. Very good staff attitude was associated with high odds of child survival as compared to average or poor staff attitude $(\mathrm{AOR}=$ $1.38, \mathrm{CI}=1.11,2.93)$, Table 4 .

$41.9 \%$ of the mothers interviewed indicated that they spent 1 hour before health staff attended to them at the facility. Waiting time of mothers was significantly associated with baby survival in the crude model but was attenuated in the adjusted model. Majority (75.2\%) of mothers were delivered by midwifes, while doctors delivered $19.8 \%$. Babies who were delivered by doctors were 2.98 times more likely to survive as compared to those delivered by traditional birth attendants, TBA $(\mathrm{AOR}=2.98, \mathrm{CI}=2.14,4.57)$. Average hours spent at labour ward by mothers was 6 hours. There was a significant association $(p=0.048)$ between hours spent at labour ward and child survival.

\section{Discussion}

Out of the 222 respondents, babies of 107 mothers representing $48.2 \%$ survived, while babies of 115 mothers (51.8\%) died. The proportion of neonatal deaths recorded in this study could however be higher than the general population, recognizing the fact that the facility where the study was conducted is a referral hospital and only worse cases might have been referred there. Nevertheless, Ghana is known 


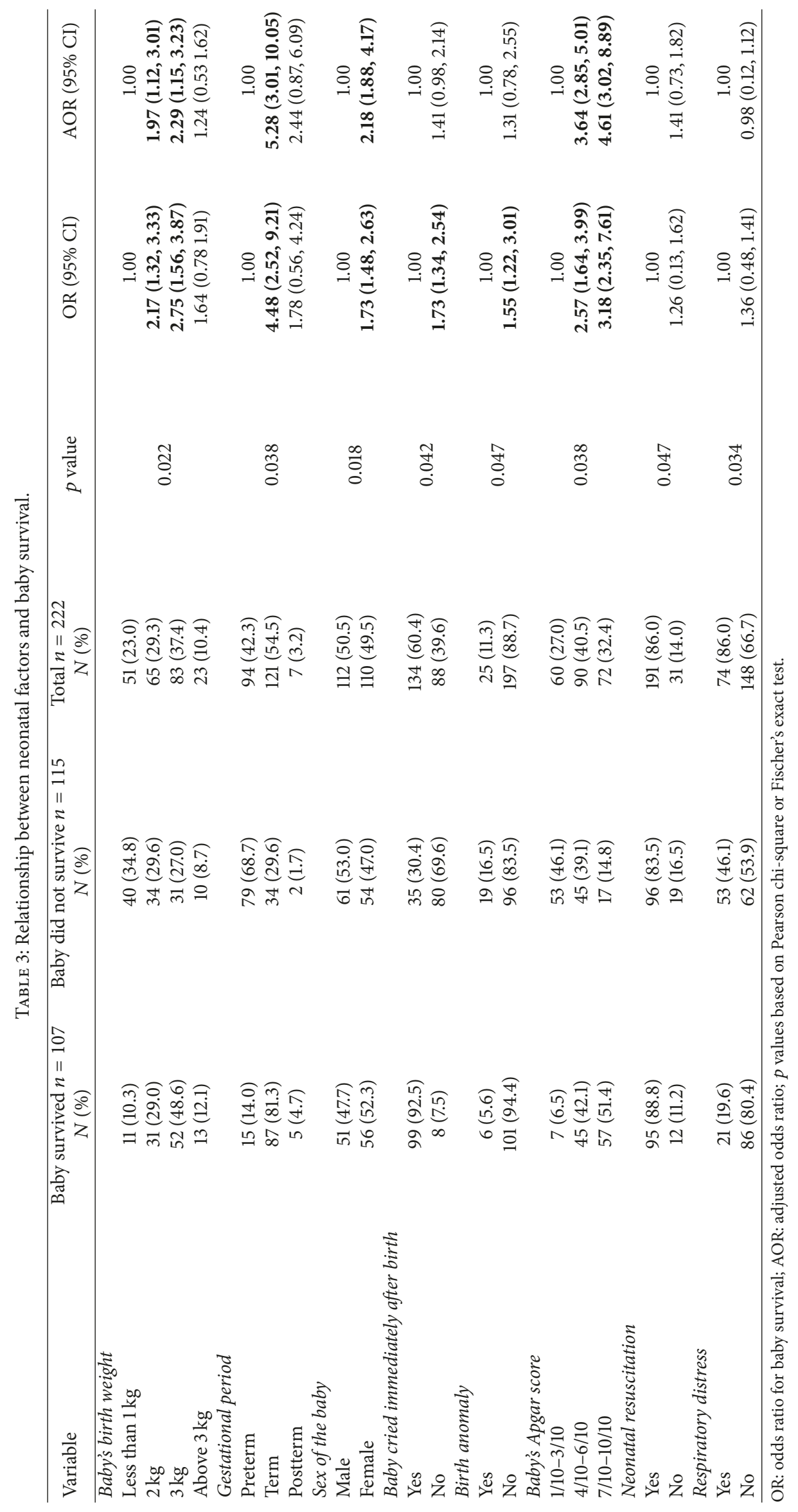




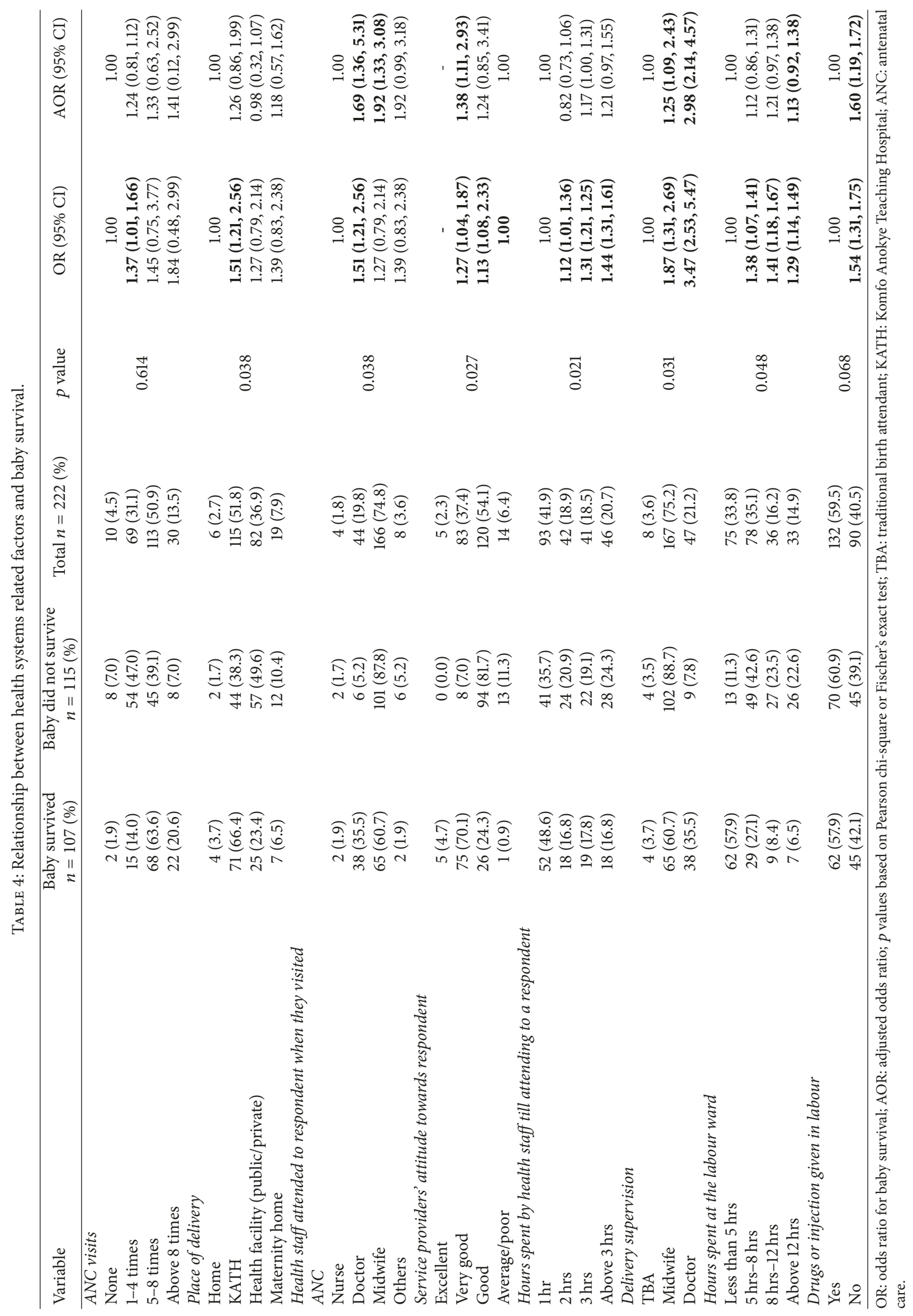


to still record high rates of neonatal mortality [16]. In corroborating Lawn et al.s findings, this study revealed that majority (53.9\%) of babies died within 1-4 days and $31.3 \%$ within 5-14 days. The babies died from asphyxia, low birth weight, prematurity, congenital anomalies, infections, and respiratory distress syndrome. WHO Report [17] indicated that major causes of newborn deaths worldwide are preterm, pneumonia/infection, asphyxia, congenital abnormalities, tetanus, diarrhoea, and others. Low birth weight, which is related to maternal malnutrition, is a causal factor in $60-80 \%$ of all neonatal deaths.

5.1. Maternal Factors Influencing Neonatal Mortality. There was a statistically significant association between mothers' parity and child survival. $47.8 \%$ and $47.0 \%$ of babies who did not survive were of primigravida and multigravida mothers, respectively. Other studies have also shown that children born after a short interval are likely to have mothers in poor health, and such children tend to have low birth weight and increased chances of neonatal mortality [18]. This is consistent with findings from a systematic review and meta-analysis that found an increased risk of preterm and neonatal and infant mortality [19]. Multigravida increases competition for family resources and attention and also increases exposure to infectious childhood diseases.

Duration of pregnancy also influenced child survival. Mothers with pregnancy duration of 35-40 weeks were more likely to have babies who will survive. This finding means that babies born before term and after term stand a high risk of not surviving. This is congruent with findings from a recent study by Mengesha et al. [20], where preterm delivery was an independent predictor of neonatal mortality in Northern Ethiopia. This could be explained by the fact that preterm and postterm babies are unable to adjust to extrauterine life and therefore are prone to specific complications like breathing difficulties, intracranial bleeding, infections, hypothermia, and jaundice [21]. This study also found an influence of pregnancy complications on child survival. Mothers who were hypertensive were more likely to have children who did not survive. As stated by Lawn et al. [22], complications during the antenatal period like pregnancy induced hypertension, eclampsia, cardiac failure, diabetes, and renal diseases cause a median increased risk of 4.5 for neonatal death, with eclampsia posing the biggest risk.

5.2. Neonatal Factors. The study revealed statistically significant relationship between birth weight and child survival. The finding corroborates findings of a study of factors affecting the survival of "at risk" newborn at Korle Bu Teaching Hospital, in Accra, Ghana, which reported that $83.6 \%$ of 128 babies weighed less than $1 \mathrm{~kg}$ died while babies weighing beyond $2 \mathrm{~kg}$ were less likely to die [23]. Gestational age (GA) is known to contribute to neonatal mortality. This study found a significant association between gestational period and child survival. This concurs with the study by Khashu et al. [24], which elaborated that infants born before 37 weeks of gestation are at greater risk of mortality compared with term newborns and attributes this directly to specific complications like breathing difficulties, intracranial bleeds, infections, hypothermia, and jaundice.

Bromen and Jöckel [25] estimated in their study that mortality rates for boys in the early neonatal period are higher than those for girls, and that biological differences between the sexes tend to result in higher male mortality than female mortality. Similarly, this current study found that, out of the 107 babies who survived, majority, 52.3\%, were females. Regression analysis slightly tilted in favour of survival of female babies.

Baby's Apgar score also proved to be relevant in child survival. There was a statistically significant association between a baby's Apgar score and child survival. This corroborates findings from the study by Li et al. [26], which found a relationship between five-minute Apgar scores and infant survival. In their study, the Apgar score showed its predictive value for infant death of both very preterm, preterm, and term infants in postneonatal period. They concluded that the Apgar score could still be a good and convenient predictor of infant death.

5.3. Health System Related Factors. Research shows that a significant number of neonatal deaths could be prevented if all women received good quality care during antenatal, delivery, and the postpartum period [27]. Majority of mothers interviewed delivered at the health facility and there was a significant association between place of delivery and child survival. These findings support the findings of Lawn et al. [22] which reported that skilled professional care during pregnancy and child birth and postnatal care are highly recommended as a critical measure to save the life of the mother and the baby. Skilled professional care during pregnancy, at birth and during the postnatal period, is as critical for both the mother and baby. Skilled attendance and institutional delivery rates are lowest in countries with the highest neonatal mortality rates [22]. Children delivered at home are likely to experience higher mortality than children delivered at the hospital or medical facilities because these facilities usually provide a sanitary environment and medical equipment to assist birth. However, home deliveries without a skilled attendant are chosen or occur for a variety of reasons, including long distances or difficult access to a birth facility, costs of services, and perceived lack of quality of care in a health facility $[12,28]$.

The general impression of respondents about staff attitude was good and there was a significant association between service providers' attitudes and child survival. Very good staff attitude increased the likelihood of child survival. A recent systematic review of literature documented a broad range of negative maternal health care providers' attitudes and behaviours affecting patient well-being, satisfaction with care, and care seeking [29]. Negative attitudes and behaviours of maternal health care providers lead to inadequate care seeking and reduce the quality of care, leading to rise in maternal and child mortality and morbidity. Majority (75.2\%) of mothers were delivered by midwifes, while doctors delivered $19.8 \%$. These figures for skilled supervised delivery are very good as they are way above the national average of 57\% [30]. Babies who were delivered by doctors were more likely to survive compared to those delivered by nurses. 
A unique strength of this study is that it provides important evidence on the predictors of neonatal mortality in Ghana. The choice of cross-sectional study design however could not permit us to make direct inferences on the relationship between the outcome variable and the covariates studied. Recruiting mothers from only one MBU could also present a selection bias and could affect the generizability of the findings. This study might also have suffered some recall bias in previous pregnancy experiences of participants. We however believed that this did not affect the study much, since our questionnaire had validation questions to most of the possible bias questions.

\section{Conclusion}

This study shows a high neonatal mortality rate in the Ashanti Region of Ghana, 51.8\%, with majority dying within 5-14 days. The causes of death included low birth weight, prematurity, congenital anomalies, infections, and respiratory distress syndrome. Findings also reveal that neonatal deaths are influenced by neonatal, maternal, and health service related factors. This suggests the need for the health service providers and other stakeholders to organize intensive health education programmes to improve awareness of the dangers that can militate against neonatal survival. Inasmuch as the education, it should target the general population using local media, ANC and PNC clinic sessions, women in second cycle institutions, and tertiary institutions. The education should highlight some significant maternal factors such as appropriate birth interval for pregnancies and the need to manage properly all infectious and noninfectious diseases. There is also the need for strengthening the health system to support mothers and their babies through pregnancy and delivery and postpartum to help improve child survival.

\author{
Abbreviations \\ MBU: Mother and Baby unit \\ MDG: Millennium Development Goal \\ MOH: Ministry of Health \\ GDHS: Ghana Demographic Health Survey \\ GHS: Ghana Health Services \\ KATH: Komfo Anokye Teaching Service \\ NMR: Neonatal Mortality Rate.
}

\section{Conflicts of Interest}

The authors declare that there are no conflicts of interest regarding the publication of this manuscript.

\section{Authors' Contributions}

Gertrude Nancy Annan conceptualized and designed the study and collected the data. Both authors analysed and interpreted the data and wrote the draft manuscript. Both authors read and approved the final manuscript.

\section{Acknowledgments}

The authors appreciate very much the support and contributions by Dr. Alex Osei-Akoto Lecturer, Head of Child Health
Department, KATH. Their suggestions and priceless editorial help motivated the authors to produce this useful work. They also thank Dr. Peter Adjei Baffour, a lecturer at the Department of Community Health, KNUST, and Mr. Emmanuel Owusu-Sekyere, a lecturer at University of Development Studies, Wa campus, for their suggestions and comments which made this work a great success. Their sincere thanks also go to the Nurse Manager and all the staff of MBU, KATH.

\section{References}

[1] T. Wardlaw, D. You, L. Hug, A. Amouzou, and H. Newby, "UNICEF Report: Enormous progress in child survival but greater focus on newborns urgently needed," Reproductive Health, vol. 11, no. 1, article 82, 2014, https://data.unicef.org/wpcontent/uploads/2015/12/Enormous-progress-in-child-survival_ 220.pdf.

[2] UNICEF, "UNICEF Data: Monitoring the situation of children and women," 2014, https://data.unicef.org/.

[3] World Health Organization, Neonatal Mortality, World Health Organization, 2017, http://www.who.int/gho/child_health/mortality/neonatal/en/.

[4] Ghana Statistical Service, Ghana Health Service, and ICF International, Ghana Demographic and Health Survey 2014, Rockville, MD, USA, 2015, https://dhsprogram.com/pubs/pdf/ FR307/FR307.pdf.

[5] World Health Organization, Neonatal Mortality Rate (per 1000 Live Births), World Health Organization, Geneva, Switzerland, 2005, http://www.who.int/healthinfo/morttables.

[6] C. Maccormack and T. S. Murphy, State of the World'S Newborns: A Report from Saving Newborn Lives, Washington, DC, USA, 2001, http://www.savethechildren.org.

[7] World Health Organization, One Million Babies Die Within 24 Hours Of Birth, World Health Organization, 2014, http://www .who.int/workforcealliance/media/news/2014/end_new_born death/en/.

[8] R. E. Black, S. S. Morris, and J. Bryce, "Where and why are 10 million children dying every year?" The Lancet, vol. 361, no. 9376, pp. 2226-2234, 2003.

[9] H. R. Chowdhury, S. Thompson, M. Ali, N. Alam, M. Yunus, and P. K. Streatfield, "Causes of neonatal deaths in a rural subdistrict of bangladesh: implications for intervention," Journal of Health, Population and Nutrition, vol. 28, no. 4, pp. 375-382, 2010.

[10] M. E. Kruk, M. Paczkowski, G. Mbaruku, H. De Pinho, and S. Galea, "Women's preferences for place of delivery in rural Tanzania: A population-based discrete choice experiment," American Journal of Public Health, vol. 99, no. 9, pp. 1666-1672, 2009.

[11] UNFPA, "Providing emergency obstetric and newborn care," 2012, [cited 2017 Jun 8], https://www.unfpa.org/sites/default/ files/resource-pdf/EN-SRHfactsheet-Urgent.pdf.

[12] K. N. Atuoye, J. Dixon, A. Rishworth, S. Z. Galaa, S. A. Boamah, and I. Luginaah, "Can she make it? transportation barriers to accessing maternal and child health care services in rural Ghana," BMC Health Services Research, vol. 15, article 333, 2015.

[13] G. B. Nuamah, P. Agyei-Baffour, K. M. Akohene, D. Boateng, D. Dobin, and K. Addai-Donkor, "Incentives to yield to obstetric referrals in deprived areas of Amansie West district in the Ashanti Region, Ghana," International Journal for Equity in Health, vol. 15, no. 1, article 117, 2016, http://equityhealthj.biomedcentral.com/articles/10.1186/s12939-016-0408-7. 
[14] W. G. Cochran, Sampling Techniques, Probability and Mathematical Statistics Applied, John Wiley \& Sons, New York, NY, USA, 3rd edition, 1977.

[15] IBM Corp Released, "IBM SPSS Statistics for Windows, Version 22.0," 2011.

[16] A. Ibrahim, "Ghana still recording high maternal, neonatal mortality," Myjoyonline, 2017, https://www.myjoyonline.com/lifestyle/ 2017/October-29th/ghana-still-recording-high-maternal-neonatalmortality-health-minister.php.

[17] World Health Organization, Newborn Death and Illness, World Health Organization, 2011, [cited 2017 Jun 26], http://www.who .int/pmnch/media/press_materials/fs/fs_newborndealth_illness/ en/.

[18] V. Sharma, J. Katz, L. C. Mullany et al., "Young maternal age and the risk of neonatal mortality in rural Nepal," Archives of Pediatrics \& Adolescent Medicine, vol. 162, no. 9, pp. 828-835, 2008.

[19] N. Kozuki, A. C. Lee, M. F. Silveira et al., "The associations of birth intervals with small-for-gestational-age, preterm, and neonatal and infant mortality: a meta-analysis," BMC Public Health, vol. 13, supplement 3, 2013.

[20] H. G. Mengesha, W. T. Lerebo, A. Kidanemariam, G. Gebrezgiabher, and Y. Berhane, "Pre-term and post-term births: Predictors and implications on neonatal mortality in Northern Ethiopia," BMC Nursing, vol. 15, no. 1, article 48, 2016.

[21] D. J. Gallacher, K. Hart, and S. Kotecha, "Common respiratory conditions of the newborn," Breathe, vol. 12, no. 1, pp. 30-42, 2016.

[22] J. E. Lawn, S. Cousens, and J. Zupan, “4 Million neonatal deaths: when? Where? Why?” The Lancet, vol. 365, no. 9462, pp. 891900, 2005.

[23] J. Welbeck, R. Biritwum, and G. Mensah, "Factors affecting the survival of the "at risk" newborn at Korle Bu Teaching Hospital, Accra, Ghana," West African Journal of Medicine, vol. 22, no. 1, 2003, https://www.ajol.info/index.php/wajm/article/viewFile/ 27981/21788.

[24] M. Khashu, M. Narayanan, S. Bhargava, and H. Osiovich, "Perinatal outcomes associated with preterm birth at 33 to 36 weeks' gestation: a population-based cohort study," Pediatrics, vol. 123, no. 1, pp. 109-113, 2009.

[25] K. Bromen and K. Jöckel, "Change in male proportion among newborn infants," The Lancet, vol. 349, no. 9054, pp. 804-805, 1997.

[26] F. Li, T. Wu, X. Lei et al., "The Apgar Score and Infant Mortality," PLoS ONE, vol. 8, no. 7, p. e69072, 2013.

[27] A. Tinker, K. Finn, and J. Epp, Improving Women's Health Issues and Interventions, Washington, DC, USA, 2000, [cited 2017 Jun 27], http://siteresources. worldbank.org/HEALTHNUTRITIONANDPOPULATION/Resources/281627-1095698140167/Tinker-ImprovingWomens-whole.pdf.

[28] Y. M. Adamu and H. M. Salihu, "Barriers to the use of antenatal and obstetric care services in rural Kano, Nigeria," Journal of Obstetrics \& Gynaecology, vol. 22, no. 6, pp. 600-603, 2002, http:// www.ncbi.nlm.nih.gov/pubmed/12554244.

[29] P. Mannava, K. Durrant, J. Fisher, M. Chersich, and S. Luchters, "Attitudes and behaviours of maternal health care providers in interactions with clients: a systematic review," Global Health, 2012, http://download.springer.com/static/pdf/749/art\% 253A10.1186\%252Fs12992-015-0117-9.pdf?originUrl=http\%3A\% 2F\%2Fglobalizationandhealth.biomedcentral.com\%2Farticle\% 2F10.1186\%2Fs12992-015-0117-9\&amp;token2=exp=1496155013
acl=\%2Fstatic\%2Fpdf\%2F749\%2Fart\%25253A10.1186\%25252Fs12992-015-0117-9.pdf $\sim$ hmac $=$ d77e3e210f683c14d05998195476264569d823c72521c3aea7446089bd576d30.

[30] Ghana Statistical Service and Ghana Health Service, "Ghana Demographic and Health Survey 2008. Ghana Statistical Service (GSS) Ghana Demographic and Health Survey," 2009. 


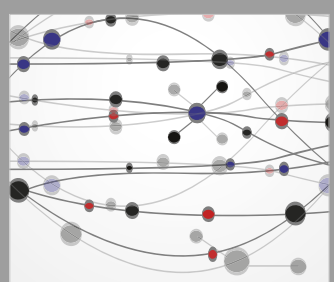

The Scientific World Journal
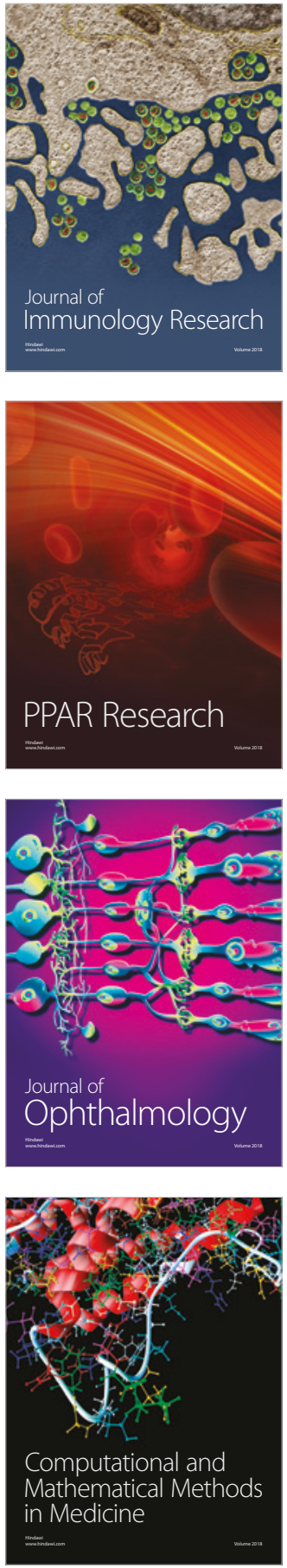

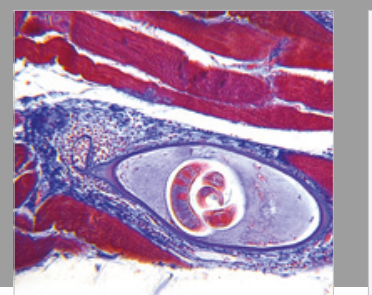

Gastroenterology Research and Practice

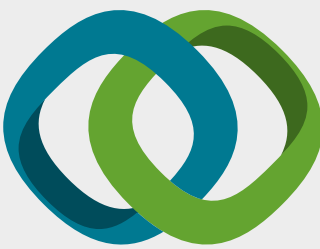

\section{Hindawi}

Submit your manuscripts at

www.hindawi.com
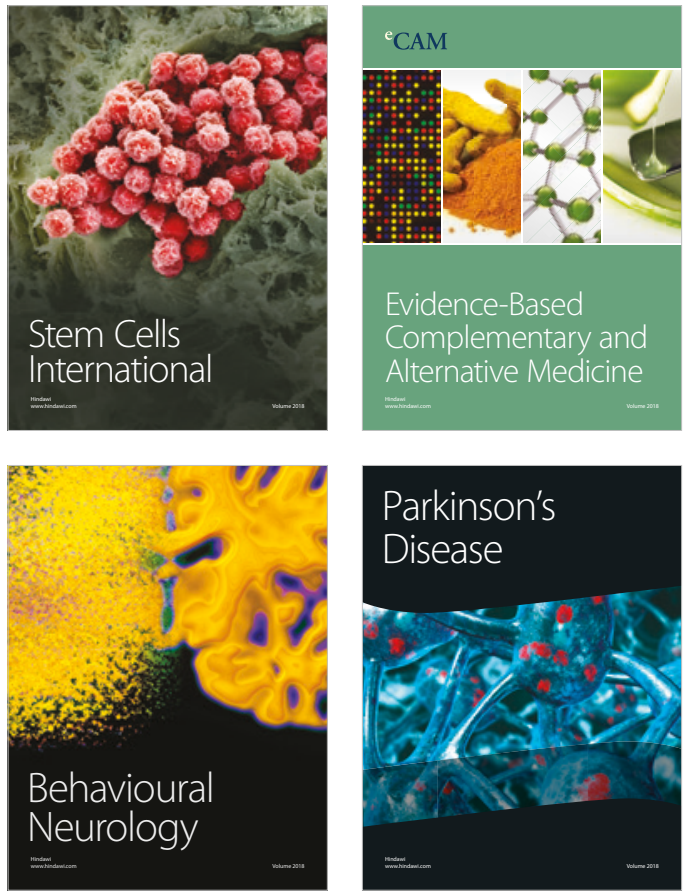

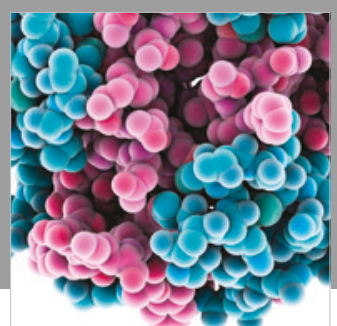

ournal of

Diabetes Research

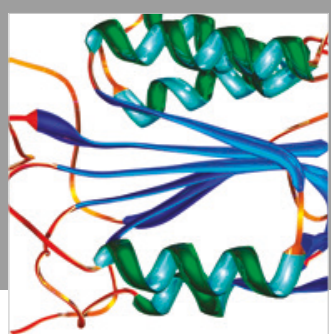

Disease Markers
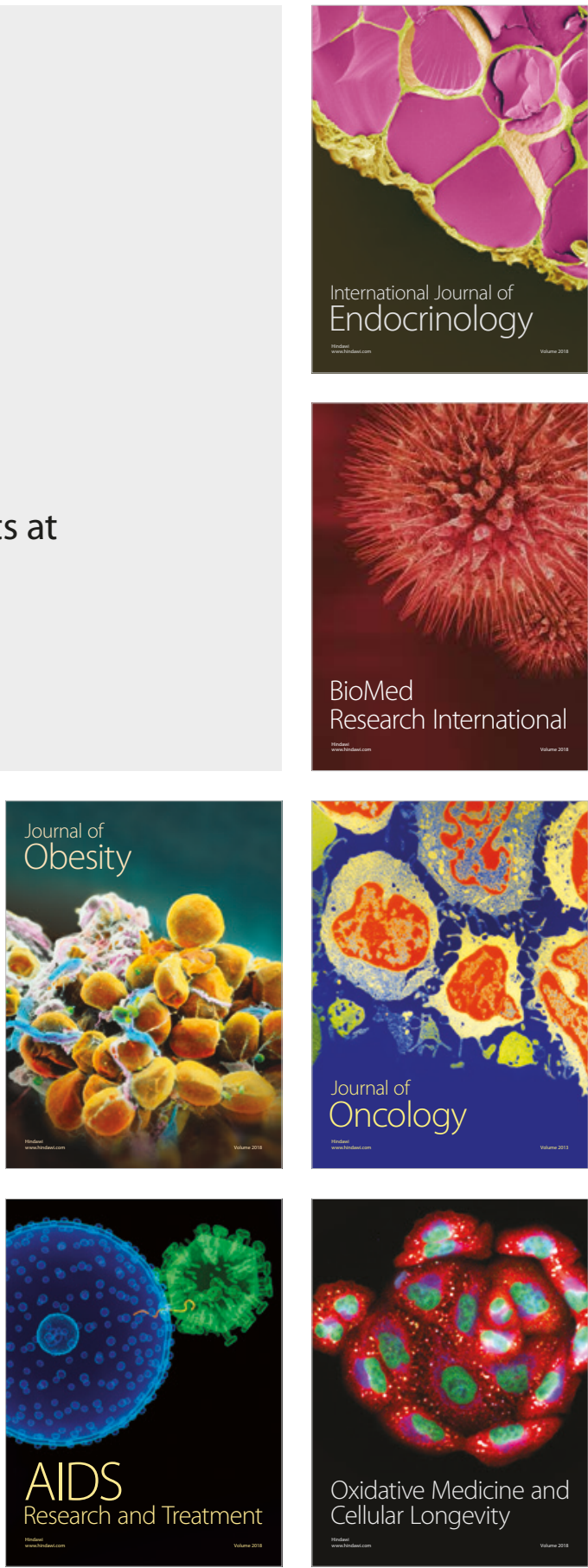